\title{
Falciparum Malaria in Febrile Patients at Sentinel Sites for Influenza Surveillance in the Central African Republic from 2015 to 2018
}

\author{
Romaric Nzoumbou-Boko $\left(\mathbb{D},{ }^{1}\right.$ Brice Martial Yambiyo, ${ }^{2}$ Carine Ngoagouni, ${ }^{3}$ Ulrich Vickos, ${ }^{4}$ \\ Alexandre Manirakiza $\left(\mathbb{D}^{1},{ }^{2}\right.$ and Emmanuel Nakouné ${ }^{4}$ \\ ${ }^{1}$ Laboratory of Parasitology, Institute Pasteur of Bangui, P.O. Box 923, Bangui, Central African Republic \\ ${ }^{2}$ Epidemiology Service, Institute Pasteur of Bangui, P.O. Box 923, Bangui, Central African Republic \\ ${ }^{3}$ Medical Entomology Service, Institute Pasteur of Bangui, P.O. Box 923, Bangui, Central African Republic \\ ${ }^{4}$ Virology Department, Institute Pasteur of Bangui, P.O. Box 923, Bangui, Central African Republic
}

Correspondence should be addressed to Romaric Nzoumbou-Boko; nzoumbou2@yahoo.fr

Received 7 January 2020; Revised 9 May 2020; Accepted 1 July 2020; Published 27 July 2020

Academic Editor: Lúcia Galvão

Copyright (C) 2020 Romaric Nzoumbou-Boko et al. This is an open access article distributed under the Creative Commons Attribution License, which permits unrestricted use, distribution, and reproduction in any medium, provided the original work is properly cited.

\begin{abstract}
Malaria is a major public health issue in the Central African Republic (CAR) despite massive scale-up of malaria interventions. However, no information is available on the incidence of malaria in febrile illness cases or on the distribution of malaria infection according to demographic characteristics, which are important indicators and valuable epidemiological surveillance tools. This study therefore aimed to characterize malaria in the network of sentinel sites set up for influenza surveillance. A retrospective analysis was conducted to explore the data from these sentinel sites from 2015 to 2018 . The Paracheck-Pf ${ }^{\circledR}$ rapid diagnosis test kit was used to screen for malaria in febrile illness cases. A total of 3609 malaria cases were identified in 5397 febrile patients, giving an incidence rate of $66.8 \%$. The age group of 1-4 years was the most affected by malaria (76.0\%). Moreover, prevalence varied across different sentinel sites, with the Bossembele Health Center, located in a rural area, showing an incidence of $96 \%$, the Saint Joseph Health Center in a semiurban area of Bangui showing an incidence of $75 \%$, and the Bangui Pediatric Complex in an urban site with an incidence of only $44.6 \%$. Malaria transmission was holoendemic over the four-year study period, and malaria incidence decreased from 2016 to 2018 . The incidence of malaria coinfection with influenza was $6.8 \%$. This study demonstrated clear microspatial heterogeneity of malaria. Malaria was consistently the most frequent cause of febrile illness. Including sites in different climate zones in the CAR will allow for a more representative study.
\end{abstract}

\section{Introduction}

In the Central African Republic (CAR), malaria is holoendemic and characterized by a high transmission rate, and the whole population (estimated at 4.7 million) is at risk for malaria infection [1]. Malaria is a major endemic illness and the leading cause of morbidity and mortality representing $50-60 \%$ of inpatient cases, with severe malaria estimated at $10 \%$ of all cases $[1,2]$. In the CAR, children and pregnant women are the most vulnerable category of malaria patients, with malaria being the leading cause of death in children under 5 years [3]. Plasmodium falciparum is the prevailing species (99\%) in Bangui, the capital city of the CAR [4]. A study carried out in Bangui identified Anopheles gambiae (63.2\%) and Anopheles funestus (33\%) as the primary malaria vectors [5].

Over the last 15 years, many initiatives have been carried out in the CAR, including the introduction of artemisininbased combination therapies as the first-line treatment of unconfirmed malaria in 2005, the distribution of longlasting insecticide-treated nets since 2010, and the introduction of a rapid diagnostic test (RDT) [6, 7]. However, despite efforts to control malaria through multiple schemes coordinated by the National Malaria Control Program 
(NMCP), malaria continues to be the major public health problem according to the scientific literature and the CAR country profile in the World Malaria Report. In 2010, two studies showed prevalence rates of $65.8 \%$ and $64.9 \%$, respectively, in children at the Bangui Pediatric Complex $(\mathrm{CPB})$ and in pregnant women in the Ouham-Pendé Prefecture $[8,9]$.

The 2019 World Malaria Report demonstrated that prevalence continued to increase in the CAR from 2015 to 2018. Prevalence rates were $68.9 \%, 71 \%, 73.3 \%$, and $72.4 \%$ in 2015, 2016, 2017, and 2018, respectively, in the CAR, and in Africa, cases increased from 199 million to 213 million during the 2015-2018 period (an increase of 7\%) [10]. Furthermore, these figures represent only the reported cases of malaria, which ignore the undetected and undiagnosed cases, especially in remote rural areas.

In the classification of malaria, the disease is called "simple" if the patient principally presents with fever, chills associated with headache, and muscle or joint pain, all of which are synonymous with an influenza-like illness $[11,12]$. In other words, there are no "typical" malaria symptoms, and the clinical picture is therefore completely nonspecific, suggesting that a patient with a "flu" syndrome including at least one of the aforementioned symptoms may suffer from malaria unless proven otherwise [13]. In most cases in Africa, as in the CAR, fever is associated with malaria and vice versa: malaria is considered as the commonest cause of fever. RDTs have been developed for malaria to improve the management of fever especially among children [11, 14]. Importantly, to date, few data have been published on the differential diagnosis of flu syndromes and malaria $[15,16]$.

In the CAR, despite the NMCP strategic plan and outlook with goals to eliminate malaria by 2030 , there are no sentinel sites for malaria surveillance activities, although disease surveillance is one of the elementary functions of public health systems [17]. Nevertheless, the Institut Pasteur in Bangui (IPB) and its Laboratory of Emerging Viruses and Zoonoses, the National Reference Center for influenza, set up a national influenza surveillance system in 2008 in collaboration with the Ministry of Health [18]. The surveillance system is based on the detection of influenza cases in a network of six sentinel sites. Here, we conducted an exploratory study to describe the cases of malaria from cases of influenza-like illnesses in these sentinel sites over the 2015-2018 period.

\section{Methods}

2.1. Type and Site of the Study. We conducted a retrospective study to analyze the malaria results in the sentinel site databases of the IPB influenza surveillance system from 2015 to 2018. The monitoring method used is described in [15]. The CAR, situated between $2^{\circ} 10^{\prime}$ and $11^{\circ} \mathrm{N}$ latitude, is an intertropical country with very diverse climates. Malaria transmission is holoendemic and occurs over the entire year, with peaks during the rainy season that occurs from April to November [19].

In 2008, two sentinel sites were opened in Bangui: at the $\mathrm{CPB}$, located in the $1^{\text {st }}$ district (center of Bangui), and at the Saint Joseph Health Center in the $7^{\text {th }}$ district (southeast
Bangui). In 2010, four other sites were opened within a maximum radius of $160 \mathrm{~km}$ around Bangui and located on the three national roads that serve the capital: the Pissa Health Center (west of Bangui), the Boali Health Center (north of Bangui), the Bossembele Hospital (northwest of Bangui), and Sibut Hospital (northeast of Bangui) (Figure 1). Due to the irregularity of the samples, the Sibut site was excluded from our study.

2.2. Study Population. The population consisted of febrile patients regardless of age or sex, visiting one of the sentinel sites for health care. The diagnosis of malaria has been systematically carried out as part of the surveillance of influenza since 2015 because malaria is the leading cause of fever in malarious areas $[11,20,21]$. We sought to compile information on patient residence (site), sex, and age.

2.3. Laboratory Screening for Malaria. The Paracheck-Pf ${ }^{\circledR}$ RDT (Orchid Biomedical Systems, India) was used. It is an immunochromatographic test based on the detection of Plasmodium falciparum-specific histidine-rich protein II (PfHRP-II) parasite antigens in lysed blood because this species is the dominant malaria parasite in the CAR.

2.4. Statistical Analyses of the Data. The data were recorded in an Access database (Microsoft Office 2016). Sentinel site maps were generated using the QGIS program (version 2.18.4), and the statistical analyses were carried out using STATA software (version 14; Stata Corp, College Station, Texas, USA).

Malaria-positive cases were estimated according to sex, age group (<1 year, $1-4$ years, $5-14$ years, $15-49$ years, and $\geq 50$ years), the sentinel site, influenza virus identification, and year. For each characteristic, the proportion of malaria cases was compared using the chi-squared test, and we determined the odds ratio (OR) to analyze the effect of each characteristic. $p$ values $<0.05$ were considered to indicate statistical significance. We described trends in the proportion of malaria cases by month and by year.

\section{Results}

3.1. Characteristics of the Study Population. During the study period, 5397 febrile patients were enrolled, including 2570 males (47.62\%) and 2822 females (52.38\%), giving a sex ratio of $0.9: 1$. The average age was 11 years (range: 2 months to 78 years). The age group of 1-4 years was the most represented (36.4\%) followed by 15-49-year-olds (23\%). The Boali Health Center registered the most patients (31.0\%) followed by the Saint Joseph Health Center in Bangui (18.8\%) and Bossembele Hospital (18.8\%). Years 2017 and 2018 showed the highest patient inclusion, with proportions of $29.0 \%$ and $32.0 \%$, respectively.

3.2. Distribution of Malaria Infection by Demographic Characteristics. In total, among the 5397 febrile patients enrolled in the sentinel site network during the four-year 


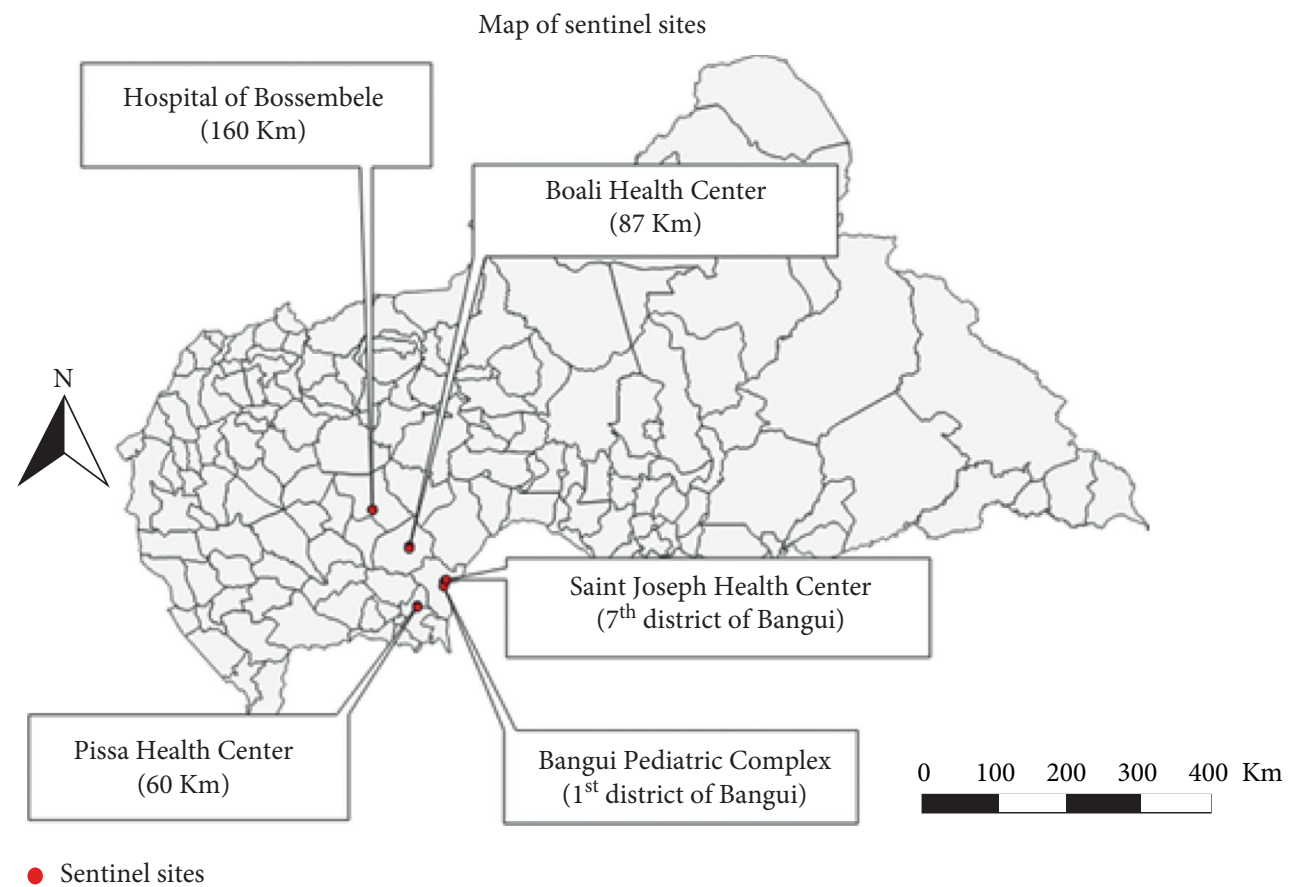

Figure 1: Map of sentinel sites for surveillance of influenza-like illness, Central African Republic, 2015-2018.

study period, 3609 malaria cases were detected, corresponding to a prevalence of $66.8 \%$. There were no differences according to sex ( $p$ value: 0.47 ). However, age groups showed significant differences: the age group of 1-4 years was the most affected by malaria $(76.0 \%)$ followed by the age group of 5-14 years (73.0\%). Under 1 year and over 50 years, prevalence was $60 \%$ and $67.0 \%$, respectively. Finally, for the age group of $15-49$ years, prevalence was $56 \%$.

Prevalence also varied among sites. Bossembele Hospital showed a prevalence of $96 \%$ followed by the Saint Joseph Health Center with $75 \%$. The Boali and Pissa Health Centers and $\mathrm{CPB}$ had prevalence rates of $62.0 \%, 52.0 \%$, and $44.6 \%$, respectively (Table 1 ).

The risk of malaria infection was highest for the age group of $1-4$ years $(\mathrm{OR}=2.2,95 \%$ confidence interval $(\mathrm{CI})$ $[1.8,2.6] ; p$ value $=0.002)$ and for the age group of $5-15$ years $(\mathrm{OR}=1.7,95 \% \mathrm{CI}[1.34,2.15] ; p$ value $=0.001)$. For sentinel sites, the risk was highest at Bossembele Hospital $(\mathrm{OR}=36.62,95 \% \mathrm{CI}[24.76,53.26] ; p$ value $=0.001)$ followed by the Saint Joseph Health Center $(\mathrm{OR}=3.6,95 \%$ CI $[2.9$, 5.52]; $p$ value $=0.001$.

The analysis of periodicity by month and year was almost homogeneous over the four-year study period (Figure 2). Furthermore, prevalence decreased over time from 2016 to 2018, dropping from $81 \%$ in 2016 to $63 \%$ in 2017 and finally to $56 \%$ in 2018 (Figure 3).

3.3. Comorbidity of Malaria and Influenza and Distribution of Influenza by Demographic Characteristics. The incidence of influenza over the four-year study period was estimated at 9.1\% (491/5397 patients), including 367 (75\%) cases of malaria-influenza coinfection. The incidence of malaria coinfection with influenza was $6.8 \%$. The influenza strains associated with coinfection were A/H3N2 (43\%), A/ H1N1pdm09 (26\%), and B (31\%). We did not observe any significant differences in the distribution of the influenza strains according to the age group $(p<0.96)$, sex $(p<0.57)$, or sentinel sites $(p<0.1)$. However, analysis of the yearly trends showed significant differences $(p<0.001)$ with strain, with the A/H3N2 strain being predominant in 2016 (58.76\%), the B strain predominating in 2017 (92.63\%), and the A/H1N1Pdm09 strain predominating in 2018 (51.35\%) (Table 2).

\section{Discussion}

Malaria prevalence according to demographic characteristics was assessed across a network of sentinel surveillance sites for influenza in the CAR between 2015 and 2018, a fouryear follow-up period. Our results showed a downward trend for malaria incidence from 2016 to 2018 in the study sentinel sites. The $66.8 \%$ malaria incidence among the influenza-like cases showed that malaria is the most frequent cause of febrile illness in the CAR, unlike some African countries where malaria ranks second or third [11].

Our study confirms that children under 5 years of age are the most vulnerable group affected by malaria. Similar results have been obtained in Imo State, Nigeria [22]. Inversely, recent studies in western Kenya and in Franceville, Gabon, have reported a gradual shift in the at-risk-formalaria age group to 7-9 and 5-14 years, respectively $[21,23,24]$. The risk of developing symptomatic malaria is effectively high in children under 5 years due to the immaturity of their immune systems $[25,26]$. Adequate protective immunity (or partial immunity), antidisease immunity, and antiparasite immunity against symptomatic malaria and $P$. falciparum appear to be acquired more slowly 
TABLe 1: Distribution of malaria infection according to demographic characteristics, Central African Republic, 2015-2018.

\begin{tabular}{|c|c|c|c|c|c|}
\hline \multirow{2}{*}{ Characteristics } & \multicolumn{5}{|c|}{ Malaria } \\
\hline & Positive, $n(\%)$ & Negative, $n(\%)$ & OR & CI $(95 \%)$ & $p$ value \\
\hline \multicolumn{6}{|l|}{ Sex } \\
\hline $\mathrm{M}$ & $1731(67)$ & $839(33)$ & & & \\
\hline $\mathrm{F}$ & $1875(66.44)$ & $947(33.56)$ & & & \\
\hline \multicolumn{6}{|l|}{ Age group } \\
\hline$<1$ year & $750(60)$ & $504(40)$ & & & \\
\hline $1-4$ years & $1497(76)$ & $465(24)$ & 2.2 & {$[1.8,2.6]$} & $0.001^{* * *}$ \\
\hline $5-14$ years & $473(73)$ & $177(27)$ & 1.7 & {$[1.34,2.15]$} & $0.001^{* * *}$ \\
\hline $15-49$ years & $697(56)$ & $548(44)$ & 0.75 & {$[0.6,0.9]$} & $0.005^{* * *}$ \\
\hline$\geq 50$ years & $192(67)$ & $94(33)$ & 1.05 & {$[0.7,1.4]$} & 0.73 \\
\hline \multicolumn{6}{|l|}{ Location } \\
\hline Bangui Pediatric Complex & $316(44.57)$ & $393(55.43)$ & & & \\
\hline Saint Joseph & $758(75)$ & $258(25)$ & 3.62 & {$[2.9,5.52]$} & $0.001^{* * *}$ \\
\hline Boali & $1042(62)$ & $632(38)$ & 2.33 & {$[1.91,2.84]$} & $0.001^{* * *}$ \\
\hline Bossembele & $979(96)$ & $36(4)$ & 36.32 & {$[24.76,53.26]$} & $0.001^{* * *}$ \\
\hline Pissa & $514(52)$ & $467(48)$ & 1.86 & {$[1.49,2.31]$} & $0.001^{* * *}$ \\
\hline \multicolumn{6}{|l|}{ Influenza } \\
\hline Negative & $3240(69)$ & $1473(31)$ & & & \\
\hline Positive & $367(75)$ & $124(25)$ & & & \\
\hline \multicolumn{6}{|l|}{ Year } \\
\hline 2015 & $825(76.53)$ & $253(23.47)$ & & & \\
\hline 2016 & $817(81)$ & $188(18)$ & & & \\
\hline 2017 & $1004(63)$ & $580(36)$ & & & \\
\hline 2018 & $963(56)$ & $767(44)$ & & & \\
\hline
\end{tabular}

*** The significant difference according to age group and location

Table 2: Distribution of influenza virus infection according to demographic characteristics, Central African Republic, $2015-2018$.

\begin{tabular}{|c|c|c|c|c|}
\hline \multirow{2}{*}{ Characteristics } & \multicolumn{4}{|c|}{ Influenza strain } \\
\hline & $\mathrm{H} 3 \mathrm{~N} 2, n(\%)$ & H1N1Pdm09, $n(\%)$ & $\mathrm{B}, n(\%)$ & $p$ value \\
\hline \multicolumn{5}{|l|}{ Sex } \\
\hline M & $102(43.04)$ & $64(27)$ & $67(28.27)$ & \multirow{2}{*}{0.57} \\
\hline $\mathrm{F}$ & $107(41.15)$ & $64(24.62)$ & $87(33.46)$ & \\
\hline \multicolumn{5}{|l|}{ Age group } \\
\hline$<1$ year & $34(42.5)$ & $16(20)$ & $30(37.5)$ & \multirow{5}{*}{0.96} \\
\hline $1-4$ years & $75(40.11)$ & $50(26.74)$ & $58(31.02)$ & \\
\hline $5-14$ years & $23(34.85)$ & $20(30.3)$ & $22(33.33)$ & \\
\hline $15-49$ years & $58(46.77)$ & $32(25.81)$ & $33(26.61)$ & \\
\hline$\geq 50$ years & $19(47.5)$ & $10(25)$ & $11(27.5)$ & \\
\hline \multicolumn{5}{|l|}{ Location } \\
\hline Bangui Pediatric Complex & $12(30.77)$ & $8(20.51)$ & $19(48.72)$ & \multirow{5}{*}{0.1} \\
\hline Saint Joseph & $52(40.94)$ & $26(20.47)$ & $48(37.8)$ & \\
\hline CS-Boali & $76(42.46)$ & $56(31.28)$ & $46(25.7)$ & \\
\hline HBOS & $42(46.67)$ & $24(26.67)$ & $22(24.44)$ & \\
\hline CS-Pissa & $27(43.55)$ & $14(22.58)$ & $19(30.65)$ & \\
\hline \multicolumn{5}{|l|}{ Year } \\
\hline 2015 & $31(41.56)$ & $31(41.56)$ & $13(16.88)$ & \multirow{4}{*}{$0.001^{* * *}$} \\
\hline 2016 & $103(58.76)$ & $20(11.3)$ & $50(28.81)$ & \\
\hline 2017 & $7(5)$ & 0 & $88(95)$ & \\
\hline 2018 & $69(45.62)$ & $76(51.35)$ & $12(2.35)$ & \\
\hline
\end{tabular}

*** The significant difference according to year.

and usually require repeated infections and intense exposure to the parasite $[27,28]$.

This shift in at-risk age groups indicates that the immunoimmaturity period has not changed and that children under five acquire malaria premunity earlier instead of gradually acquiring immunity. The control efforts for this age group should target decreased and interrupted exposure to reduce the number of malaria episodes, which cause the shift in the premunity period, and therefore the change in the at-risk group. However, our group of 15-49 years did not appear to be very at-risk, demonstrating acquired immunity in subjects inhabiting endemic areas after intense and uninterrupted exposure to malaria. 


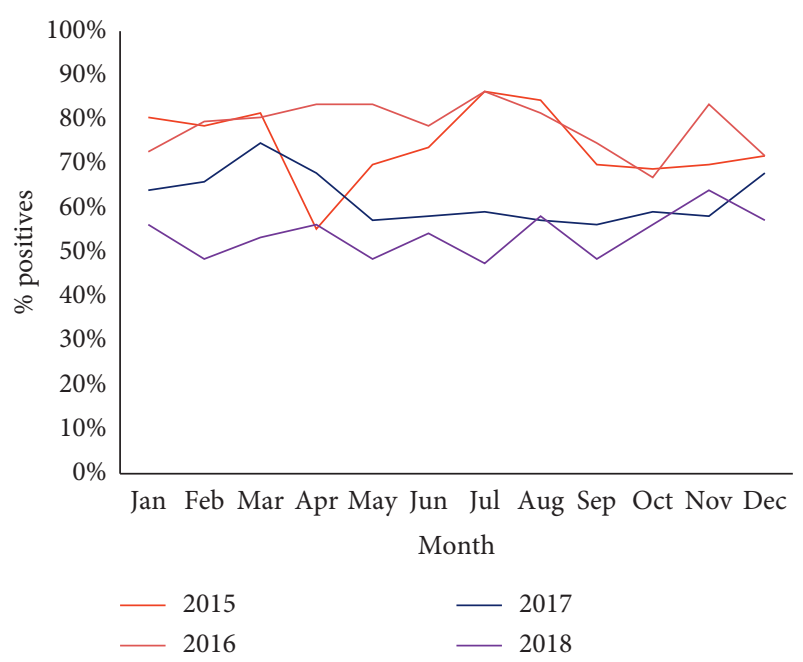

FIgURE 2: Monthly distribution of malaria incidence, Central African Republic, 2015-2018.

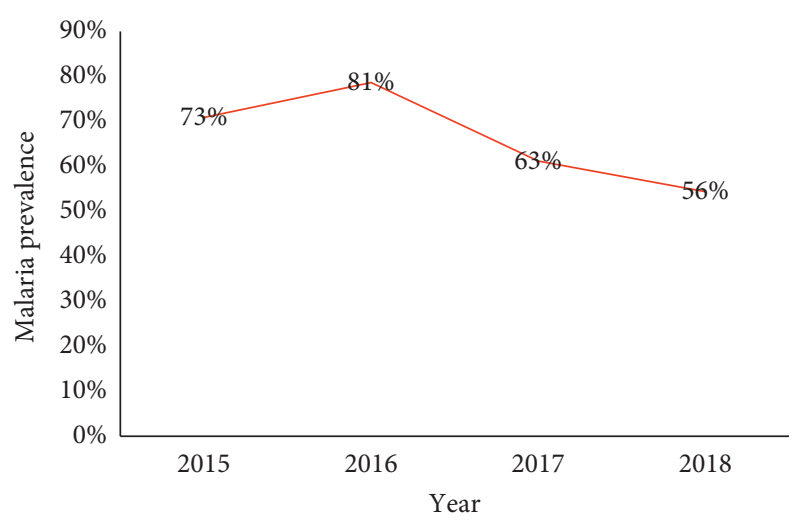

Figure 3: Yearly distribution of malaria, Central African Republic, 2015-2018.

Statistical analyses revealed spatial variability in malaria prevalence. At the two sites located in the city of Bangui, the Saint Joseph Health Center $\left(7^{\text {th }}\right.$ district) showed a higher prevalence than the CPB ( $1^{\text {st }}$ district). Interestingly, the first entomological inventory of malaria vectors carried out in Bangui indicated an abundance of A. gambiae sensu lato and A. funestus in Ouango in the $7^{\text {th }}$ district [5]. The higher prevalence of these vectors in the $7^{\text {th }}$ district of Bangui can also be explained by the abundance of preferential breeding sites for mosquitos because in this district, various types of activities such as fish farming and brick making for the construction of houses, as well as the lack of plumbing, favor stagnant water. Furthermore, the $7^{\text {th }}$ district is considered a semiurban area, and similar results have been reported in Gabon, showing relatively high prevalence or transmission in semiurban areas compared with urban areas [29].

The Bossembele site, a rural area located at the edge of a savannah, showed high prevalence with 36 times of higher risk of transmission compared with the $\mathrm{CPB}$. Again, this result echoes work in Gabon, showing a higher prevalence in rural areas than in semiurban and urban areas [29]. Bossembele is also situated at the intersection of national roads No. 1 and No. 3 that lead to Chad and Cameroon, suggesting that there is a relatively heavy population flow.

The difference in the frequency and regularity of malaria that is defined by the transmission rate at each site can also be due to epidemiological facies [30]. The network of sentinel sites included equatorial facies, tropical facies, urban facies, and the facies of local or transient events. However, in the absence of updated geographical data, particularly with regard to the climate and also entomological factors in this area, it is not possible to determine any relationship with malaria prevalence. Regarding Pissa, located in an area forming a part of the forest zone in the southern part of the CAR, our results indicate a relatively low risk of transmission.

Overall, our results highlight the microspatial heterogeneity of malaria in the CAR. A study conducted in Kenya showed that the spatial heterogeneity of malaria reduces the effectiveness of control strategies [31]. Therefore, it is also important to assess the specificity of each area in the context of the CAR to implement objective and effective interventions. Thus, sentinel sites should be set up in different climate zones of the CAR to assess spatial dynamics at the national level.

The monthly malaria prevalence was remarkably homogeneous, despite alternation between a rainy season (May-October) and a dry season (November-April). This lack of seasonal effect on transmission is surprising because the temperature and humidity conditions during the rainy season are favorable for the multiplication of immature malaria vectors (mosquito larvae) and therefore synonymous with high transmission. In contrast, studies in Burkina Faso, Ghana, and Kenya show seasonal transmission, varying with meteorological factors [32-34]. Nonetheless, the current climate change likely affects malaria dynamics, hence underlining the importance of carrying out smallscale studies throughout the country to assess the impact of microclimates.

Although the network of sentinel sites was set up for influenza, malaria is proving to be one of the major causes of febrile episodes at these sites. The prevalence of malaria coinfection with influenza, $6.8 \%(n=5397)$ during the study period, is similar to a malaria-influenza coinfection study in Kenya, with a prevalence of $4-8 \%$ among children under 5 years of age [35]. Our data did not reveal any disparities in influenza strains according to the age group, sex, or sentinel site. In contrast, the prevalence of the A/H1N1Pdm09 strain was the highest in children under 5 years in the CAR network of sentinel sites during the 2010-2015 period [18]. The lack of literature on malaria-influenza coinfection does not allow us to assess the relevance of the malaria-influenza coinfection. Our study nonetheless illustrated that this network of sentinel sites can be used as syndromic epidemiological surveillance sites for several febrile diseases, such as arboviruses, in addition to malaria and influenza. Other infectious diseases such as salmonellosis and diarrheal diseases can also be monitored using the same operational resources. 
In the case of malaria, the collection of dried blood spot samples at these sites will make it possible to not only determine the circulating Plasmodium species but also help characterize strains of $P$. falciparum and look for signatures of drug resistance included in the National Malaria Control Protocol.

\section{Conclusion}

Our analysis showed a relative decrease in malaria prevalence at selected influenza surveillance sites from 2015 to 2018. Malaria was consistently the most frequent cause of febrile illness. Transmission is still holoendemic. The age group of 1-4 years is at higher risk and shows high prevalence. Microspatial heterogeneity was observed in Bangui and in provincial cities. In addition, rural areas are more at risk and showed a higher prevalence than those in semiurban and urban areas. The study of malaria-influenza coinfection requires improved diagnosis of pathologies with febrile symptoms. The inclusion of sites in different climate zones in the CAR will allow for a more representative study.

\section{Data Availability}

The Microsoft Excel data used for this study are available from the corresponding author upon request.

\section{Ethical Approval}

Influenza surveillance is included in the surveillance of diseases with epidemic potential, and this surveillance program was approved by the Ministry of Health expert committee (Decree 0277/MSPP/CAB/DGSPP/DMPM/ SMEE of 5 August 2002) in the absence of the national institutional ethics committee, which did not exist when the study began.

\section{Consent}

Verbal consent was obtained from all patients, and the data were used in strict confidentiality.

\section{Conflicts of Interest}

The authors declare that they have no conflicts of interest.

\section{Acknowledgments}

The sentinel surveillance system in the Central African Republic was supported financially by the Department of Health and Human Services, USA. The authors thank health professionals at various health centers and hospitals belonging to the sentinel site network of the Central African Republic.

\section{References}

[1] Severe Malaria Observatory, "Central African Republic," 2020, https://www.severemalaria.org/countries/centralafrican-republic.
[2] Ministère de la Santé et de la population, "Politique national de lutte contre le paludisme de la RCA, programme national de lutte contre le paludisme," 32 pages, Ministère de la Santé et de la population, Geneva, Switzerland, 2016.

[3] Ministère de la Santé et de la population, "Plan de transition du secteur santé en République Centrafrique 2015-2017," p. 95, Ministère de la Santé et de la population, Geneva, Switzerland, 2015.

[4] D. Djallé, J. C. Gody, J. M. Moyen et al., "Performance of Paracheck $^{\mathrm{TM}}-\mathrm{Pf}$, SD Bioline malaria Ag-Pf and SD Bioline malaria Ag-Pf/pan for diagnosis of falciparum malaria in the Central African Republic," BMC Infectious Diseases, vol. 14, no. 1, 109 pages, 2014.

[5] M. O. Ndiath, K. Eiglmeier, M. L. Olé Sangba et al., "Composition and genetics of malaria vector populations in the Central African Republic," Malaria Journal, vol. 15, p. 387, 2016.

[6] Ministère de la santé publique, "Plan stratégique national de lutte contre le paludisme 2012-2016," Ministère de la santé publique, de la population et de la lutte contre le VIH, RCA, Geneva, Switzerland, 2012.

[7] World Health Organization, Profile Central African Republic, World Malaria Report 2012, p. 3, World Health Organization, Geneva, Switzerland, 2012.

[8] G. Bobossi-Serengbe, J.-C. Gody, R. Fioboy, J.-B. Elowa, and A. Manirakiza, "Comparaison de l'efficacité de l'artémether et de la quinine dans le traitement du paludisme grave chez les enfants à Bangui, République centrafricaine," Bulletin de la Société de pathologie exotique, vol. 108, no. 2, pp. 107-111, 2015.

[9] L. Ruckstuhl, C. Lengeler, J. M. Moyen, H. Garro, and R. Allan, "Malaria case management by community health workers in the Central African Republic from 2009-2014: overcoming challenges of access and instability due to conflict," Malaria Journal, vol. 16, no. 1, p. 388, 2017.

[10] World Health Organization, World Malaria Report 2019, World Health Organization, Geneva, Switzerland, 2019, https://www.who.int/publicationsetail/world-malaria-report2019.

[11] U. Dalrymple, E. Cameron, S. Bhatt, D. J. Weiss, S. Gupta, and P. W. Gething, "Quantifying the contribution of Plasmodium falciparum malaria to febrile illness amongst African children," eLife, vol. 6, Article ID e29198, 2017.

[12] M. P. Grobusch and P. G. Kremsner, "Uncomplicated malaria," Current Topics in Microbiology and Immunology, Springer, vol. 295, pp. 83-104, , Berlin, Germany, 2005.

[13] I. A. Clark, L. M. Alleva, A. C. Mills, and W. B. Cowden, "Pathogenesis of malaria and clinically similar conditions," Clinical Microbiology Reviews, vol. 17, no. 3, pp. 509-539, 2004.

[14] World Health Organization, World Malaria Report 2012, World Health Organization, Geneva, Switzerland, 2012, https:/www.who.int/malaria/publications/world-malaria-report-2012/report/en/.

[15] J. N. Waitumbi, G. J. Domingo, K. M. Neuzil et al., "Outpatient upper respiratory tract viral infections in children with malaria symptoms in western Kenya," The American Journal of Tropical Medicine and Hygiene, vol. 83, no. 5, pp. 10101013, 2010.

[16] M. Yazdanbakhsh and P. G. Kremsner, "Influenza in Africa," PLoS Medicine, vol. 6, no. 12, Article ID e1000182, 2009.

[17] S. M. Teutsch and R. E. Churchill, Principles and Practice of Public Health Surveillance, Vol. 406, New York Oxford University Press, Oxford, UK, 2nd edition, 2000. 
[18] A. Manirakiza, M. Y. Batoumbou Ketta, U. Vickos et al., "Sentinel surveillance of influenza-like illness in the Central African Republic, 2010-2015," Archives of Public Health, vol. 75, p. 61, 2017.

[19] D. Menard, F. Yapou, D. Djalle, A. Talarmin, and A. Manirakiza, "Frequency distribution of antimalarial drugresistant alleles among isolates of Plasmodium falciparum in Bangui, Central African Republic," The American Journal of Tropical Medicine and Hygiene, vol. 74, no. 2, pp. 205-210, 2006.

[20] U. Dalrymple, E. Cameron, R. Arambepola et al., "The contribution of non-malarial febrile illness co-infections to Plasmodium falciparum case counts in health facilities in subSaharan Africa," Malaria Journal, vol. 18, p. 195, 2019.

[21] S. Maghendji-Nzondo, H. Nzoughe, G. J. Lemamy et al., "Prevalence of malaria, prevention measures, and main clinical features in febrile children admitted to the Franceville regional hospital, Gabon," Parasite, vol. 23, p. 32, 2016.

[22] S. E. Oluchi, R. A. Manaf, S. Ismail, and T. K. Udeani, "Predictors of health-seeking behavior for fever cases among caregivers of under-five children in malaria-endemic area of Imo state, Nigeria," International Journal of Environmental Research and Public Health, vol. 16, no. 19, Article ID E3752, 2019.

[23] A. Kapesa, E. J. Kweka, G. Zhou et al., "Utility of passive malaria surveillance in hospitals as a surrogate to community infection transmission dynamics in western Kenya," Archives of Public Health, vol. 76, no. 1, p. 39, 2018.

[24] H. N. Njuguna, J. M. Montgomery, L. Cosmas et al., "Malaria parasitemia among febrile patients seeking clinical care at an outpatient health facility in an urban informal settlement area in nairobi, Kenya," The American Journal of Tropical Medicine and Hygiene, vol. 94, no. 1, pp. 122-127, 2016.

[25] S. Portugal, S. K. Pierce, and P. D. Crompton, "Young lives lost as B cells falter: what we are learning about antibody responses in malaria," The Journal of Immunology, vol. 190, no. 7, pp. 3039-3046, 2013.

[26] E. M. Billig, W. P. O’Meara, E. M. Riley, and F. E. McKenzie, "Developmental allometry and paediatric malaria," Malaria Journal, vol. 11, no. 1, p. 64, 2012.

[27] C. Rogier and J.-F. Trape, "Malaria attacks in children exposed to high transmission: who is protected?" Transactions of the Royal Society of Tropical Medicine and Hygiene, vol. 87, no. 3, pp. 245-246, 1993.

[28] T. Staalsoe and L. Hviid, "The role of variant-specific immunity in asymptomatic malaria infections: maintaining a fine balance," Parasitology Today, vol. 14, no. 5, pp. 177-178, 1998.

[29] S. Maghendji-Nzondo, L. C. Kouna, G. Mourembou et al., "Malaria in urban, semi-urban and rural areas of southern of Gabon: comparison of the Pfmdr 1 and Pfcrt genotypes from symptomatic children," Malaria Journal, vol. 15, no. 1, p. 420, 2016.

[30] J. Mouchet, P. Carnevale, M. Coosemans et al., "Typologie du paludisme en Afrique," Santé: Cahiers d'Etudes et de Recherches Francophones, vol. 3, no. 2, pp. 220-238, 1993.

[31] P. Bejon, T. N. Williams, C. Nyundo et al., "A micro-epidemiological analysis of febrile malaria in Coastal Kenya showing hotspots within hotspots," eLife, vol. 3, Article ID e02130, 2014.

[32] Y. Yé, M. Hoshen, C. Kyobutungi, and R. Sauerborn, "Local scale prediction of Plasmodium falciparum malaria transmission in an endemic region using temperature and rainfall," Global Health Action, vol. 2, no. 1, Article ID 1923, 2009.
[33] S. Ankamah, S. Kaku Nokoe, and W. A. Iddrisu, "Modelling trends of climatic variability and malaria in Ghana using vector autoregression," Malaria Research and Treatment, vol. 2018, Article ID 6124321, 11 pages, 2018.

[34] D. O. Apat, J. M. Gachohi, M. Karama, J. R. Kiplimo, and S. E. Sachs, "Temporal variation in confirmed diagnosis of fever-related malarial cases among children under- 5 years by community health workers and in health facilities between years 2013 and 2015 in Siaya County, Kenya," Malaria Journal, vol. 16, no. 1, p. 454, 2017.

[35] M. G. Thompson, R. F. Breiman, M. J. Hamel et al., "Influenza and malaria coinfection among young children in western Kenya, 2009-2011," The Journal of Infectious Diseases, vol. 206, no. 11, pp. 1674-1684, 2012. 